by the students who present themselves for instruction in science and technology.

Broadly, the work of the evening classes may be grouped under the heads of (I) mathematics and science, (2) technology, (3) commerce and economics. A fair number of students, however, study languages and other literary subjects.

In addition to the classes in the various branches of study in cluded under physics there is a three years' course in electrical engineering, and workshop classes are arranged for the fourth and succeeding years in electric wiring, fitting, \&c. Courses in telegraphy and telephony are to be held later to supplement the other work.

Students in the department of engineering begin with elementary machine drawing, and are only admitted to the mechanical engineering lectures after they have made a certain amount of progress in such drawing. There is also workshop practice in fitting and machining, smith-work and patternmaking. Students work for two or three evenings a week in the shops, at a regular course of filing, chipping, scraping, \&c. and are not allowed to go to the machines till they have proved their efficiency at hand work.

The department for the building trades is probably the most numerously attended, a natural result of the fact that these trades are strongly represented in the neighbouring localities. An endeavour is made to get all technological students to go through a course of building construction and to acquire an elementary acquaintance with mathematics, practical geometry, and experimental science. A short course of lectures on the chemistry of building materials is given: Classes in builders quantities and quantity surveying are held, and practical work is done in the brick-work and plumbing shops. A collection of specimens of various woods arranged for students' inspection at any time, and practical work in masonry, plasterers' work, house-painting and decorating, complete the facilities placed at the disposal of all engaged in the building trade.

In addition to a very complete course of lectures and practical work in pure inorganic and organic chemistry, there have been arranged in the chemical department, lectures to trade class students on various technical applications of chemical and physical science, and a course of elementary experimental science, given by the Principal and the Head of the physical clepartment. This simple course forms an introduction to the more systematic work in the chemical and physical departments, as well as providing the necessary preliminary training for students of technology.

The department of commerce and economics at present in cludes classes in book-keeping, shorthand, type-writing, and general commercial subjects. French and German are also extensively studied.

The women's department is in an undeveloped condition. Needlework, dressmaking, and millinery are the only subjects for which provision has yet been made. With the completion of the new buildings, now being erected, the organisation of classes in cookery, laundry-work, and general housewifery will be brought to perfection, and a day school of domestic economy will be started.

The Northern Polytechnic has, in addition to the students already referred to, a number working for University degrees, and many studying literature, vocal and instrumental music, elocution, and other subjects of a similar more or less recreative character.

The rapid increase of the numbers seeking admission has already raised a difficulty as to accommodation, and for the 2000 individual students at present enrolled every available inch of space has had to be utilised.

A. T. Simmons.

\section{THE DUKE OF DEVONSHIRE ON THE SECONDARY EDUCATION BILL.}

A DEPUTATION representing a conference held in Manchester under the auspices of the Victoria University on the subject of secondary education, was received on Friday las by the Duke of Devonshire, Lord President of the Council, the object of the deputation being to present to the Lord President the following resolutions, which were passed at the Manchester Conference :-

(I) That, in the opinion of the conference, a Minister of Education of Cabinet rank should represent the Education Department in Parliament ; (2) that the creation of the consultative committee mentioned in Clause 3 of the Bill should be obligatory, and that the committee should be so composed as to be competent to advise as well on the various grades of technical as on those of secondary education ; $(3)$ that it is desirable that immediate provision be made for the institution of local authorities for secondary education; (4) that the relations of the proposed board of education to the Charity Commissioners should be more clearly defined in the Bill, so as to avoid as far as possible the risk of dual control.

We print, from the Times report, an abridgment of the speech delivered by the Duke on the occasion.

As to the resolutions they had brought before him, he was happy to see that the first one practically endorsed the action of the Government in relation to the Bill which was introduced last year. The Bill which will shortly be introduced will probably be altered in some respects as to the constitution of the new Education Department ; but he hoped that such alteration would make it more satisfactory than even the provisions of the Bill of last Session.

The subject upon which Principal Bodington chiefly spoke was that of the second resolution relating to the appointment and constitution of a consultative committee. Principal Bodington said that a certain amount of apprehension had been felt in some quarters that the assumption by the Government of supervision or control over secondary education might possibly have the effect of crushing out the individuality which has hitherto characterised the secondary school system, and might tend in the direction of undue uniformity. $\mathrm{He}$ could assure them that no such idea has entered into the minds of the present Government, and that they are perfectly aware, and feel as strongly as it is possible to feel, that it would be in the very highest degree undesirable to attempt, in relation to secondary education, to establish any such uniformity of system as must, perhaps necessarily, exist as regards primary or elementary education. And in so far as the appointment of an advisory committee may tend to make it impossible. that any such result may follow, he attached very considerable importance to the constitution of such a committee. Principal Bodington admitted, howeverand that is a point on which he felt equally strongly-that the appointment of the committee must not be allowed in any degree to impair the responsibility of the Minister himself.

It would, he thought, be a very unfortunate departure from our constitutional system if the Minister were able to feel that he was not absolutely and entirely responsible for the action of his department, and if he were able to take shelter under the advice of the consultative committee, however representative that committee might be.

As to the constitution of the consultative committee by the Bill to be introduced, he did not think it would be desirable to enter into too minute details. Words, however, he thought, might very well be inserted in the clause setting forth that the intention is to give it that representative character-representative of the Universities, representative of other parties interested in education, representative of the teachers themselves, as well as persons directly nominated by the Government,

Secondary education ought probably in the new department to have a sub-department of its own ; and technical education prob. ably will remain, for the present, at all events, more closely connected with the Science and Art Department. Secondary education is concerned with boys and youths; technical education is concerned with youths and people of more advanced age; and he doubted very much whether it would be possible, with. out unduly enlarging the size of the consultative committee, to entrust to the committee duties connected with both secondary and technical education.

Not much had been said by the deputation on the subject or the third resolution-the institution of local authorities for secondary education. He trusted that anybody who did him the honour to read the speech he made on the subject last year will recognise that the Government are not in the smallest degree insensible to the urgency of the constitution of these authorities. If they refrained this Session from embodying proposals on that subject in the measure which constitutes the central authority, it would be for the reason stated last year.

$\mathrm{He}$ could give the strongest assurance that nobody could feel more than the Government that a measure which does not deal with the constitution of local authorities must necessarily be an utterly inadequate and imperfect one, and that it is the Government's firm intention, if they should be successful in passing the 
Bill constituting the central authority this year, to introduce one for the constitution of local authorities next year.

The question of the relations of the proposed Board of Education to the Charity Commissioners was an extremely diff. cult one. He thought the provisions relating to the subject in the Bill of this year might probably differ in some respects from those in last year's Bill ; and he hoped that any alterations that might be made in them might be in the direction which the deputation had indicated and appeared to desire. He did not anticipate much difficulty in obtaining assent to the general principle of the Bill. When they came to its details he had no doubt that some difference of opinion might be developed, and he would be very happy to have an opportunity of taking the advice of some of the gentlemen who composed the deputation, and who would be so competent to render it.

\section{THE ORIGIN OF ATMOSPHERIC ELECTRICITY. ${ }^{1}$}

$A$ LMOST every suggestion that has ever occurred to any one as to the origin of atmospheric electricity, and the part it plays in meteorology, has been tested over and over again during the past century with only negative results. Some of these are noted in the following paragraphs :

Volta and De Saussure suggested the evaporation of the natural waters on the surface of the globe, all of which are more or less impure, but Pouillet showed that electricity could not come from the evaporation of pure water, but might come from salt water and also from the evaporating surfaces and chemical changes incident to vegetation. De la Rive showed that vegetation was entirely insufficient, and Reiss showed that evaporation of salt water does not, of itself; produce electricity ; on the other hand, he showed that the friction of drops of water against the sides of a platinum vessel would produce a small amount.

The hypothesis that our electricity comes from the action of the sun in heating the atmosphere, as also that it is produced by the friction of warm air against cold air, have both been examined, but experiment has never been able to demonstrate the slightest trace of thermo-electricity in gases and vapours.

Schoenbein considered that the oxygen of the air might act electro-chemically upon the molecules of water of which the clouds are composed; but this again has received no experimental confirmation, and.could hardly account for the electricity that we find in the clearest dry air. E. Becquerel suggests the decomposition of organic matters; but this, also, is not considered sufficient. : It is, recognised on all sides that the evaporation of terrestrial waters may carry the negative electricity at the surface of the ground upwards into the atmosphere; but this does not explain the origin of that electrified state at the surface, nor the fact that the atmosphere remains positive while the earth remains negative.

Be la Rive considered that the continual chenical action taking place in the interior of the globe explains the origin of terrestrial electricity, and that, as beneath the ocean this action is due to infiltration of sea water, therefore, the ocean is charged with positive electricity, but the solid continents with negative. Especially in the equatorial regions would the atmosphere receive from the sea those positively electrified vapours which, after overflowing into the two hemispheres, would descend in the polar regions and produce auroras, lightning, \&c. But this fascinating and comprehensive theory seems to be not at all in harmony with the recent careful observations as to the nature of the electrical distribution in latitude and over oceans and continents. It is generally acknowledged that a great amount of electrified vapour and dust is carried up in every volcanic eruption; but although the quantity is enormous, yet it is not sufficient to explain the condition of the whole atmosphere, although we may thereby explain some of the variations in its general electrified condition; this volcanic electricity apparently originates in a variety of ways, especially from friction.

The fact that a magnetised body when in motion gives rise by induction to an electric current flowing through a neighbouring conductor has.led Rowland and S. P. Thompson to calculate the electric effect of motions, such as the wind blowing over the surface of a magnetised globe, or the effect of the rotating magnetic earth upon the ether of space in its neighbourhood. But here again the electric effect. turns out to be too small.

1 By Prof. Cleveland Abbe. (Reprinted from the U.S. Monthly Weather Review, June 1898 .

$$
\text { NO. I 532, VOL. 59] }
$$

The discovery by Arrhenins that sunlight, especially the ultraviolet rays, greatly diminish the insulating power of dry air and produce what is called photo-electric dissipation and the phenomena discovered by Hallwachs, that a conductor carrying a negative charge gives it up to the surrounding gas when struck by a ray of ultra-violet light, have given rise to the idea that in this way the sunlight acting upon one-half of the earth's atmosphere may discharge the electricity therefrom as well as from the earth and ocean beneath the air ; but this, again, has not yet been demonstrated by experiment.

Faraday and Sohncke have shown that dry crystals of ice, such as may occur in the coldest dry air, may become positively electrified by friction, as, for instance, by descending through the air, and Sohncke has formulated a theory explanatory of the electricity of thunderstorms as dependent upon the behaviour of cirrus and cumulus clouds. The electricity is generated in the region of the isothermal surface of $32^{\circ} \mathrm{F}$., but this ingenious view still waits for its confirmation. Brillouin has advanced an ingenious explanation of the origin of atmospheric electricity, based upon the action of ultra-violet light upon the crystals of ice that constitute cirrus clouds (see Monthly Weather Review for 1897, p. 440), but some points in his theory remain to be established by further experimentation. P. de Heen suggests that as solar radiation illuminates and heats the earth, so it also has the power to electrify the upper strata of air ; that these, in fact, as it were, absorb the electric influence, and then, being electrified, act indirectly on the ground below. Maclean and Lenard have studied the electrification of the air by drops of water falling through it. It is found that falling water drops give the air a negative charge, but so also do snow crystals ; therefore the higher strata of air should be negative instead of positive, as actually observed. Marvin observes that a rain of fine drops of mercury in dry air electrifies the drops and presumably the air. Palmieri has shown that the condensation of aqueous vapour in and of itself does not develop electricity. Gay Lussac and Pouillet did the same for all changes of condition from solid to fluid to vapour to gas, and the reverse ; no electricity is developed except in the change from fluid to solid, when some solids, such as sulphur, show slight manifestations which are due to the action of the edge of the solidifying liquid on the glass vessel containing it.

The inductive action of the earth on its atmosphere is undoubtedly important, but the action of the sun, distant as it is, may be appreciable. Edlund and Siemens have advocated the solar origin of atmospheric electricity, but their hypothesés have not yet been generally accepted.

The spread of the electro-magnetic telegraph lines and the electric cables over the globe has shown that local electric currents generally flowing in an east-west direction exist everywhere in the earth, thus suggesting that the electrified condition of the atmosphere depends upon them. Clerk Maxwell, in his treatise on electricity, after recognising that all other sources are insufficient, suggests that possibly the changing pressures to which the earth's crust is subjected by tidal strains may give rise to piezo-electricity sufficient to explain the negative charge of the earth ; the editor, quite independently of Maxwell, has elaborated this hypothesis in his "Preliminary Studies." The laws of these tidal strains have been studied by Chree, Davison, Darwin, and others.

The thermo-electric currents of Peltier and the piezo-electricity so fully investigated by Gaugain are not sufficient to explain the amount of electricity represented by the currents flowing through the earth's surface, but the piezo-electric currents due to tidal strain may be quite sufficient. The latter represent the conversion of gravity into electricity.

Lord Kelvin, without touehing the question as to the ultimate origin of the electrified state, shows that observed phenomena are sufficiently explained by simply recognising the fact that the atmosphere can be treated as the dielectric of a condenser (like the glass between the two sheets of tinfoil in a Leyden jar); the lower or earth's surface is negative, and the upper layer of the atmosphere is positively electrified.

But without pursuing further the maze of hypotheses as to the ultimate origin of the electrified state of the atmosphere, we must conclude that this problem is too difficult for immediate solution; it is one of many that a following generation of physicists will undoubtedly cope with successfully.

If we turn to the simpler question of the meteorological phenomena that are evidently associated with atmospheric elec. tricity, we shall find that the best physicists are not yet wholly 